\title{
PLANNING OF THE AMOUNT OF TRAINS NEEDED FOR TRANSPORTATION BY RAIL
}

\author{
Jonas Jonaitis \\ Dept of Transport Management, Vilnius Gediminas Technical University, Plytinès g. 27-407, \\ LT-10105 Vilnius, Lithuania.E-mail: Jonas.Jonaitis@ti.vgtu.lt
}

Received 12 December 2006; accepted 1 February 2007

\begin{abstract}
The article analyses the importance of planning process of rail transportation. Railway planning problems are presented in this paper. Planning the railways for years, months, weeks or days ahead leads to substantially different problems; in this regard railway planning problems can be strategic, tactical, operational and short-term. Another way to classify railway planning problems is based on their target: they concern the timetable, the rolling stock and the crew. Planning the structure and volume of the rolling stock is a key factor in achieving maximum efficiency of transportation by rail as well as forecasting the demand for these transport facilities. The demand for trains is a time-dependant variable which in each case should be determined by two main approaches. The first method allows us to determine quantitative parameters of rolling stock (i.e. kilometers logged, efficiency, turnover, etc.). The second is based on specially developed mathematical models relying on qualitative characteristics such as relative expenses, efficiency of the particular train, relative expenditure of resources, cost of the trains, etc.
\end{abstract}

Planning the volume of the rolling stock the determination of optimal service life of the trains plays an important role. The calculations involve repair costs, number of overhauls, current expenses and operational characteristics.

Keywords: rail transport, trains, rolling stock, planning.

\section{Introduction}

For many years, railway companies did not have to face much competition in public passenger and freight transportation. In the past decades, this changed drastically. The railways lost a large part of their market share to automobiles. Recently, air traffic took over many middle- and long-distance train travellers. In addition, a directive of the European Union required opening the national railway market in the 90's. Until then, most state-owned railway companies in Europe had been the only ones to provide railway services in their countries; after liberalising the market, they had to compete for the customers. These developments urge the railway companies to attract more customers by raising their service level and to cut their costs by working more efficiently. Improving their planning process contributes to reach both of these goals $[1,2]$.

Railway companies are nearly inexhaustible sources of planning problems. Until recently, all of them have been dealt with manually; many are still handled without automation and optimisation. Railway applications soon attracted the attention of mathematical research. Many of the problems are of a combinatorial character and suitable for operations research methods. Conversely, problems of railway practice have an influ- ence on operations research by showing interesting and useful directions to extend existing methods and to explore new ones. In the last decade, more and more computer-aided tools turned out to improve the railway planning process significantly. Besides intensive research, the virtually exponential increase of computational power contributes a lot to these successful applications. Nonetheless, comparing the number of existing operations-research-based planning tools to the plenty of railway problems indicates that there shall be enough railway-related research topics for a long time. Also, mathematical research shall certainly continue on railway optimization topics that have not been addressed so far. In any case, it shall be exciting to see to what extent railway planning can be automated and optimised in the coming years and decades [3, 4].

Developing strategies for effective national transportation by rail the existing structure of rolling stock should be analyzed and possible changes predicted. The rolling stock and the demand for it make a variable which may be calculated by the particular techniques. Some of them rely on the present situation when it is necessary to calculate the stock based on available quantitative data of the kilometers logged, efficiency, turnovers, etc. The particular mathematical models are being developed for its qualitative evaluation taking 
into account relative expenses, the efficiency and cost of the particular rolling stock, and the like. Based on the above models it is possible to determine the optimal structure of the rolling stock as well as to predict its development and trade tendencies [5-7].

Making plans with account of possible changes in the rolling stock the optimal service life should also be determined, taking into consideration repair expenses, overhauls, current expenses and other maintenance factors $[8,9]$.

\section{Planning process of rail transportation}

Planning the railways for years, months, weeks or days ahead leads to substantially different problems; in this regard railway planning problems can be strategic, tactical, operational and short-term [1].

Strategic planning has a planning horizon of several years or even decades, the main focus is on capacity planning.

Tactical planning allocates the available capacity with a planning horizon of 2 months, up to a year.

Operational planning sets up the fully detailed plans, the planning horizon varies from 3 days to 2 months. Mainly, it concerns adjusting the tactical plans for the forthcoming weeks.

Short-term planning comprises problems that arise when the actual train operations take place or just before that. It covers planning steps with a planning horizon of 3 days, at most.

Another way to classify railway planning problems is based on their target: they concern the timetable, the rolling stock and the crew. Timetabling answers the questions which locations are to be connected by direct trains and when the trains have to run. Rolling stock planning determines how many locomotives and passenger carriages are needed and how to use them for trains. Crew scheduling of most passenger railway operators concerns the questions how many train drivers and conductors are needed and how to assign them to the trains. These three topics include problems of very different characteristics. Timetabling determines the railway network while crew and rolling stock scheduling allocate the available resources. But the requirements for crew and rolling stock planning differ substantially, too. For example, rolling stock units are bound to the tracks so they can block the way through a station for each other. Crew has much more exhibility as train drivers and conductors can just walk from one platform to another. However, crew scheduling has to respect wishes of the employees, sometimes at the cost of efficiency. A well-known recent example of that is the case of the cost-efficient crew schedules of the major Dutch passenger railway operator Nederlandse Spoorwegen (NS) in 2001 which turned out to be unacceptable for train drivers and conductors. This example is commonly referred to as "rondje om de kerk" (around the church) since in the cost-efficient schedules the daily workload of the employees often contains only trains on a single trajectory back and forth.
The employees' wishes result in very complex requirements for the crew schedules; the rules of rolling stock planning are usually simpler.

Of the wide spectrum of railway planning problems, this thesis deals with rolling stock planning in the tactical, operational and short-term phase. Here we give a brief overview of rolling stock planning; for the sake of completeness we also include strategic planning.

Strategic planning determines the amount of rolling stock needed in the future. In the other planning stages, the available rolling stock is to be assigned to the timetable services. Tactical, operational and shortterm planning take different levels of detail of reality into account, so the requirements that the schedules have to fulfil differ for the planning phases. Tactical planning produces the basic shape of the weekly schedule, operational planning refines this for the actual calendar weeks. Short-term planning modifies these schedules to comply with some requirements that are not dealt with in earlier planning phases. Moreover, short-term planning supervises the execution of the schedules.

The three major objectives in rolling stock planning are service quality, operational costs and robustness $[10,11]$. A good service quality means that trains have enough seat capacity to cover the passenger demand. Also, rolling stock on inter-city trains with many long-distance passengers is expected to provide more comfort than regional trains. A higher service quality encourages more travellers to use the train instead of their cars. When running the trains, railway operators have rolling stock related expenses such as electricity or fuel consumption and maintenance costs; efficient schedules minimise these expenses. Everyday railway operations have to face with disruptions and delays; robust rolling stock schedules are less affected by them.

Robustness of the schedules can be increased when the number of possible sources for delays is kept low and spreading of delays is prevented as much as possible. Hence the rolling stock schedules can also contribute to raising the punctuality of the railway system. Of course, these criteria contradict one another; the operators have to find a good balance between them.

Strategic and tactical planning only consider these criteria. In operational and short-term planning, however, time is often too short to look for a schedule that matches best the objective criteria above. More important in such cases is to come up quickly with a solution that fulfils the requirements and that ensures an acceptable level of service quality, efficiency and robustness.

The Lithuanian railway sector joined the European Union together with the whole country, and the transition period is basically over. Development of new legislation and implementation of economic reforms has brought great results.

Since the main components of the market economy have been reinforced in the transport field, further goals and objectives are to be determined in the long-term development strategy (up to 2015) [12]. 
With a view of ensuring further focused development of the railway sector, aimed at its complete integration into the European market of transport services and development of a safe, efficient and environmentally friendly transport system, the Lithuanian strategic national railway plan for 2005-2015 was prepared. The purpose of the plan is to guide long-term decision making regarding the development of the national railway infrastructure and systems as well as the future needs for the rolling stock and maintenance/repair facilities. The plan will be used to prioritize and justify investments in the Lithuanian railway sector.

The global objective of the Strategic National Rail Transport Development Plan for 2005-2015 is to establish and evaluate the guidelines based on which the long-term decisions shall be taken regarding the development of national railway infrastructure as well as future needs for rolling stock and relevant maintenance/repair facilities.

The strategic plan analyses different infrastructure and rolling stock modernisation options including the scope of the option, assessments of the related costs and benefits from a technical, operational, economic and financial viewpoint. Different implementation scenarios and timeframes are also analysed. lude:

Specifically the objectives of the strategic plan inc-

- analyses of the current services offered;

- evaluation of the current potential of the Lithuanian railway transport services based on Lithuania's and regional macro-economic conditions;

- analyses of the present physical conditions of infrastructure and rolling stock and evaluation of the difference between Lithuanian and EU specifications;

- identification of internal and external factors and evaluation of their impact on Lithuanian railway transport;

- identification of the future demand for Lithuanian railway transport in relation to the range of services to be rendered and the future technical parameters of infrastructure and rolling stock, hereunder the fulfilment of the EU directives for interoperability;

- preparation of long-term development visions for Lithuanian railway transport taking the EU accession into account;

- preparation of proposals for gradual modernisation of Lithuanian railways and their compliance with the EU requirements.

In transportation by rail the serviceability of locomotives and other traction facilities determining the intensity, safety and efficiency of freight and passenger transportation play an important role. At present the locomotives, diesel and electric trains are used in Lithuania for this purpose. The locomotives (249) relying on internal combustion diesel engines and electric drives make a major part of them.

The volume of planned freight and passenger transportation is a decisive factor of rational use of the rolling stock [13, 14]. In determining the demand for the locomotives, the efficiency of their operation should also be known.

In 1997 JSC "Lithuanian Railways"(LG) purchased 51 head wagons of European standard which have already been used. This enabled "Lithuanian Railways" to join the European stock of freight wagons (RIV) accepting their standards of wagon usage and stock- taking. The stock of head wagons and locomotives in 2001-2005 is illustrated in Table 1 [12].

Table 1. Locomotives and wagons in JSC "Lithuanian Railways"

\begin{tabular}{|l|c|c|c|c|c|}
\hline $\begin{array}{l}\text { At the end of } \\
\text { the year }\end{array}$ & 2001 & 2002 & 2003 & 2004 & 2005 \\
\hline Locomotives & 265 & 254 & 254 & 251 & 249 \\
\hline $\begin{array}{l}\text { Electrical, } \\
\text { diesel trains } \\
\text { and railcars }\end{array}$ & 63 & 61 & 60 & 62 & 62 \\
\hline $\begin{array}{l}\text { Freight } \\
\text { wagons: }\end{array}$ & 9362 & 9396 & 9308 & 9250 & 9309 \\
\hline Covered & 2174 & 2083 & 2008 & 1991 & 1980 \\
\hline Platform & 942 & 799 & 525 & 373 & 232 \\
\hline $\begin{array}{l}\text { High-sided } \\
\text { wagons }\end{array}$ & 1834 & 1834 & 1826 & 1818 & 1817 \\
\hline Tanks & 1888 & 1889 & 1870 & 1875 & 1883 \\
\hline Other & 2524 & 2791 & 3079 & 3193 & 3397 \\
\hline $\begin{array}{l}\text { Passenger } \\
\text { carriages: }\end{array}$ & 537 & 509 & 480 & 475 & 467 \\
\hline $\begin{array}{l}\text { Electric } \\
\text { traction }\end{array}$ & 111 & 111 & 96 & 96 & 96 \\
\hline $\begin{array}{l}\text { Diesel } \\
\text { traction }\end{array}$ & 194 & 184 & 184 & 183 & 183 \\
\hline
\end{tabular}

The future development of rolling stock is a process of adapting its volume to the market needs and qualifying its technical, ecological and economic features by using state-of-the-art technical solutions or technologies. It includes replacement of the main components during upgrading, procurement of new types and elimination of worn-out stock.

Renewal of the locomotive stock includes replacement of power units in respective locomotive, addition of new stock by procurement and appropriate reduction of the amount of respective stock $[13,14]$.

LG envisages replacement of power units with new power-blocs in 126 freight locomotives. Besides, LG intends to procure 34 new freight locomotives to replace the old type and to allow higher train loads. In addition, LG is going to procure 12 new passenger train locomotives with central heating generators to replace the old TEP-60 type. The total costs for the locomotive stock renewal amounts to approximately 220 mill. $€$.

In general, the future freight wagon stock should contain fewer universal and more specialized wagons. This adaptation should be accomplished by procurement of modern specialised wagons and elimination of worn-out units. LG plans to renew about half of the wagon stock for an estimated cost of 120 mill. $€$.

The program for wagon stock renewal is illustrated in Table 2. 
The amount of wagons available at present would satisfy the needs for transportation. However, most of them require repair, while some should be written off.

Table 2. Freight wagon stock adaptation

\begin{tabular}{|l|c|c|c|c|c|}
\hline $\begin{array}{c}\text { Wagons to } \\
\text { procure }\end{array}$ & 2005 & 2006 & 2007 & 2008 & $2009-2020$ \\
\hline $\begin{array}{l}\text { Half-boarded } \\
\text { open }\end{array}$ & 0 & 60 & 60 & 60 & 610 \\
\hline Tanker & 0 & 0 & 0 & 0 & 1000 \\
\hline Fertilizer & 300 & 50 & 50 & 50 & 400 \\
\hline Grain & 0 & 80 & 80 & 80 & 960 \\
\hline
\end{tabular}

It is estimated that this plan could be combined by eliminating outmoded wagons, including nearly 800 half-boarded open cars, 820 tankers, 75 fertilizer and 410 grain transporters, depending on procurement. About 100 more wagons could be scrapped due to their high age (higher than 40 years).

The demand for wagons was calculated determining the average number of loaded wagons accepted and transferred per day (twenty four hours) and multiplying the sum obtained by the average wagon turnover in the particular period of time assuming that the latter is going to decrease (i.e. in 2005 - 4.5 days ( 24 hours each), in 2010 - 3.9 days and in 2015 - 3.3 days). The demand for specialized wagons was determined based on the expected demand for transportation of the particular type of cargo which is the main factor on which the demand depends.

\section{Calculating the amount of the rolling stock needed for transportation by rail}

In recent years, the methods described in literature $[5,6]$ which had been created for calculating the traction rolling stock some years ago have been widely used. The above calculations are based on the coefficient of the demand for locomotives as well as on the demand on the particular route or for the rolling stock as a whole. Further we will consider the ways of calculating the railway wagons by the most accurate approach based on the time (hours) of the wagon as a constituent part of the train, the time of cargo transfer and maintenance or repair time:

$$
n_{d}=\frac{1}{24}\left(\frac{\sum n s}{v_{r}}+\sum n_{k} t_{k}+\sum n_{t} t_{t}\right)
$$

where $\frac{\sum n s}{v_{r}}$ - wagon-hours; $\sum n s$ - distance run by the wagons (wagons $-\mathrm{km}$ ); $v_{r}-$ train speed on the route $(\mathrm{km} / \mathrm{h}) ; \sum n_{k} t_{k}$ - wagon-hours (cargo transfer); $\sum n_{t} t_{t}$ - wagon-hours (maintenance).

Wagon stock with respect to an average distance run per day:

$$
n_{d}=\frac{\sum n_{k} s_{k}+\sum n_{t} s_{t}}{s_{B}} .
$$
day:

Wagon stock with respect to the efficiency per

$$
n_{d}=\frac{\sum p l}{F_{B}} .
$$

The volume of the wagon stock operating at present can be determined based on wagon turnover per day $\vartheta$ (in days) and the work $u$ (for the particular route) or relying on an average cargo transfer per day in the wagons $\sum u_{p}$ (for the whole railway system), that is:

$$
n_{d}=\vartheta u
$$

or:

$$
n_{d}^{\prime}=\vartheta \sum u_{p}
$$

The inventory stock of freight wagons may be determined in this way:

$$
n_{\text {inv }}=n_{d}(1+\beta) \text {, }
$$

where $\beta-$ a coefficient to determine the number of wagons out of operation $\beta=0.1-0.2$.

The stock of passenger wagons in operation is as follows:

$$
n_{s k}^{p}=m z \vartheta_{\text {sast }},
$$

where $m$ - average number of wagons in the train; $z-$ number of wagons on the route per day; $\vartheta_{\text {sast }}-$ turnover of passenger trains.

The inventory stock of passenger wagons may be found in this way:

$$
n_{i n v}^{p}=n_{s k}^{p}\left(1+\beta_{s k}+\beta_{s p e c}\right),
$$

where $\beta_{s k}-$ coefficient to determine the number of reserved or broken wagons $\beta=0.06-0.09 ; \beta_{\text {spec }}-$ coefficient to determine specialized wagons $\beta=0.01-0.02$.

The calculations made by the above formula are based on the use of various coefficients, therefore their accuracy may range to some extent.

Theoretical analysis of rolling stock may rely on the following statement: a variant requiring minimal total forced expenses should be chosen from a set of the alternative rolling stock structural patterns and purchasing variants ensuring the achievement of the final goal (i. e. good transportation in due time and at the costs specified).

Assuming the condition of linearity, the model may be expressed in this way:

$$
\begin{aligned}
& \min \sum_{i, j} c_{i j} x_{i j} \\
& \sum_{j} a_{i j} x_{i j} \geq b_{i} ;
\end{aligned}
$$




$$
\begin{aligned}
& \sum_{i, j} d_{i j}^{m} x_{i j} \leq R^{m} \\
& x_{i j} \geq 0,
\end{aligned}
$$

where $x_{i j}$ - the number of $j$-type trains used to carry products $i$ (type of cargo, type of transportation): $c_{i j}$, $a_{i j}, d_{i j}^{m}$ - relative forced expenses, efficiency of the particular train and relative expenditure of resource $m$ in carrying $i$-type cargo by $j$-type train, respectively.

The model (9)-(12) can not adequately describe the actual process.

First, the relative expenses $c_{i j}$ depend on the structure of the rolling stock $x_{i j}$, being, in fact, non linear. Therefore, they should be described as follows:

$$
\begin{aligned}
& \sum_{i} c_{i j} x_{i j}=\sum_{i} \tilde{c}_{i j} x_{i j}+E K_{j} y_{j} \mathrm{sn} y_{j} ; \\
& y_{j} \equiv x_{j}-x_{j}^{0}+x_{j}^{B},
\end{aligned}
$$

where $\tilde{c}_{i j}$ - average operational expenses in $i$-type transportation by $j$-type rolling stock (train); $K_{j}-$ cost of a rolling stock; $y_{j}$ - purchasing of $j$-type rolling stocks $\left(x_{j}^{0}-\right.$ at the beginning of the year; $x_{j}^{B}-$ purchasing completed).

The value (13) introduced is:

$$
\operatorname{sn} y=\left\{\begin{array}{l}
1, \text { if } y \geq 0 \\
0, \text { if } y<0
\end{array}\right.
$$

Therefore, the model (9) should be replaced by (13)-(15)

Second, the above model is static, not taking into account the dynamics of transportation, wearing of the locomotives, strategies of their replacement and changes with time. In addition, the optimal technical parameters and maintenance characteristics should be chosen, which is of special importance when service life is considered. The latter is a decisive factor in determining the number of trains to be purchased.

Let us consider an optimal model of rolling stock replenishment. Let us suppose that changing of technical and economical parameters is a discrete process, with each train operating in the same mode for some time, then being transferred to another mode of operation because of aging. New trains are put into operation and old ones written off only at the end of the year. To simplify the model, let us assume that both the trains used and cargo transported are of the same type. (However, the above simplification does not bring about any radical changes, making the formulation even more complicated, therefore, it may be omitted).

Let $\tau$ represent service life of the train; $r$ - operation mode; $N_{\tau r t}$ - number of trains with $\tau$ years of service operating in the year $t$ of the planned period; $N_{\tau r t}$ - number of trains operating in mode $r$. Trains of each type are characterized by the efficiency current expenses $I_{\tau r t}$ (which can be referred to those of renovation or repair, if necessary), replenishment cost $K_{\tau t}$ and dismantling (reduction) balance (cost of scrap metal minus reduction expenses $L_{\tau t}$ ).

Based on the assumptions made, the replenishment of the rolling stock may be described by the following model:

$$
\begin{aligned}
& \sum_{t \geq 1} \frac{K_{0 t} N_{0 t}}{(1+E)^{t-1}}+\sum_{t \geq 1 \tau \geq 1 r} \sum_{i} \frac{I_{\tau r t} N_{\tau r t}}{(1+E)^{t}}-\sum_{\tau \geq 1} L_{\tau 1}\left(N_{\tau-1}^{0}-\right. \\
& \left.N_{\tau 1}\right)-\sum_{t \geq 2} \sum_{\tau>1} \frac{L_{\tau t}\left(N_{\tau-1, t-1}-N_{\tau t}\right)}{(1+E)^{t-1}} \rightarrow \min
\end{aligned}
$$

for the constraints:

$$
\begin{aligned}
& \sum_{\tau \geq 0} \sum_{r} N_{\tau r t} P_{\tau r t} \geq V_{t}, \quad t \geq 1 ; \\
& \quad \sum_{r} N_{\tau r t}=N_{\tau t}, \quad t \geq 1, \quad \tau \geq 0 ; \\
& N_{\tau 1} \leq N_{\tau-1}^{0}, \quad \tau \geq 1 ; \\
& N_{\tau t} \leq N_{\tau-1, t-1}, \quad \mathrm{t} \geq 2, \quad \tau \geq 1,
\end{aligned}
$$

where $V_{t}$ - planned demand for transportation to be satisfied by trains during the year $t ; N_{\tau}^{0}$ - number of trains of $\tau$ service life, when $t=0 ; K_{0 t}, N_{0 t}$ - number and cost of new trains in the year $t$.

In economic terms, (16)-(20) it may be described in the following way. The efficiency function (16) tends to minimize the total major and current expenses to $t=0$ (1st and 2nd terms, respectively) by subtracting the sum obtained in dismantling trains during the whole period of renewal. The inequality (17) means the requirement to fully satisfy the demand for transportation. The inequality (18) shows that the number of trains operating in different modes should be equal to the total number of trains for a given time of operation. The balance inequalities (19)-(20) demonstrate that the number of trains of $\tau$ service life in the year $t$ should not exceed that of the trains of $(\tau-1)$ service life in the last year of the planned period of time.

The model (16)-(20) enables us to determine not only the optimal structure of the rolling stock and purchase order, but the rate of the development of a given transport facility and trading tendency as well.

\section{Model for determining the optimal service life of rolling stock}

During their service life the rolling stock should bring profit to a state - owned or private company which may optimize their work based on the local efficiency criterion. This criterion may be taken as minimum relative expenses equated based on time factor and the moment of train purchasing, i. e. being, in fact, the relationship between the expenses on train purchas- 
ing, overhauls and operational expenses (minus dismantling balance) and the total volume of transportation carried out by all trains during their operation time.

Let us consider a model for determining the optimal service life of the train in accordance with the minimum relative forced expenses. As it had been done before, let us take a model where the process of wearing is discrete, implying that during each year the technical and economic parameters of the trains are considered to be constant, while at the turn of the year they abruptly change.

The costs of purchasing the trains, as well as the expenses on their overhauls and maintenance during the year $\tau$, minus the sum obtained after their dismantling (elimination) at the end of the last year of their service life, equated to those existing at the moment before their purchasing, based on the time factor, are equal to:

$$
K+\sum_{m=1}^{M} \frac{R_{m}}{(1+E)^{\tau_{m}}}+\sum_{t=1}^{T} \frac{I(t)}{(1+E)^{t}}-\frac{L}{(1+E)^{T}},
$$

where $K$ - initial cost of the trains; $R_{m}$ - cost of repair; $\tau_{m}$ - the year when repairs are to be made; $M$ - number of overhauls; $I(t)$ - current expenses (without those of renovation) for the trains operating in the year $t ; L-$ cost of train dismantling (elimination).

The volume of transportation equated to that existing before train purchasing, based on the time factor, is equal to:

$$
\sum_{t=1}^{T} \frac{P(t)}{(1+E)^{t}},
$$

where $P(t)$ - the efficiency of trains in the year $t$ of their operation.

The optimal service life $T$ should correspond to the minimum expenses on carrying the unit of cargo, i. e.:

$$
\min _{T} \frac{K+\sum_{m=1}^{M} \frac{R_{m}}{(1+E)^{\tau_{m}}}+\sum_{t=1}^{T} \frac{I(t)}{(1+E)^{t}}-\frac{L}{(1+E)^{T}}}{\sum_{t=1}^{T} \frac{P(t)}{(1+E)^{t}}} .
$$

The functions describing the changes in current expenses and the efficiency of trains for any cycle of operation, i.e. including the time from new train purchasing to the first overhaul as well as from the first until the second overhaul, etc. may be of various nature. The value of the above functions depends on the time of operation calculated not from the moment of train purchasing but from starting the cycle of operation. Therefore, the summation should be made for each particular cycle. In addition, when decreasing relative expenses with respect to service life, minimization should be done for every operational period, with account of overhauls performed and the time of their duration. Taking into account the above considerations, we get (23) written as follows:

$$
\operatorname{minmin}_{T M, \tau_{m}} \frac{K+\sum_{m=1}^{M} \frac{R_{m}}{(1+E)^{\tau_{m}}}+\sum_{m=0}^{M} \sum_{t=1}^{t=\tau_{m+1}-\tau_{m}} \frac{I(t, m)}{(1+E)^{t+\tau_{m}}}-\frac{\mathrm{L}}{(+E)^{T}}}{\sum_{m=0}^{M} \sum_{t=1}^{t=\tau_{m+1}-\tau_{m}} \frac{P(t, m)}{(1+E)^{t+\tau_{m}}}},
$$

where $I(t, m)$ - functions describing the changing of current expenses and train efficiency, depending on train service life considered from the moment when overhaul $\mathrm{m}$ was performed; $m=0$-corresponds to the moment of new train purchasing; $\tau_{M+1}=T$.

As we can see, the costs of overhauls, their duration and intervals play an important part in developing the models for determining the optimal service life of rolling stock.

\section{Conclusions}

1. Developing strategies for effective national transportation by rail the existing structure of rolling stock should be analyzed and possible changes predicted.

2. Planning the railways for years, months, weeks or days ahead leads to substantially different problems; in this regard railway planning problems can be strategic, tactical, operational and short-term.

3. The global objective of the Strategic National Rail Transport Development Plan for 2005-2015 is to establish and evaluate the guidelines based on which the long-term decisions shall be taken regarding the development of national railway infrastructure as well as future needs for rolling stock and relevant maintenance/repair facilities.

4. The rolling stock and the expected demand for trains make a variable. The calculations should regularly be made to determine the amount and type of trains needed at the particular time to ensure efficient freight and passenger transportation.

5. The calculation techniques used to determine the rolling stock have been mainly based on quantitative characteristics of trains. However, the methods relying on the evaluation of such qualitative characteristics as relative expenses, the efficiency of the particular train, its cost, etc. are also available.

6. The determination of the optimal service life of the rolling stock taking into account the costs of overhauls, their duration and intervals enables us to forecast more precisely the demand for trains.

\section{References}

1. MAROTI, G. Operations research models for railway rolling stock planning. Eindhoven Technical University, 2006. 199 p.

2. GOOSENS, J. H. M. Models and algorithms for railway line planning problems. $\mathrm{Ph}$. D. thesis. University of Maastricht, Netherlands, 2004. 169 p.

3. GROOT, R. Minimum circulation of railway stock. Master's thesis. University of Amsterdam, Netherlands, 1996. $142 \mathrm{p}$. 
4. ABBINK, E. J. W.; VAN DER BERG, B. W. V.; KROON, L. G.; SOLOMON, M. Allocation of railway rolling stock for passenger trains. Transportation Science, 2004, Vol 38, No 1, p. 33-42.

5. BAUBLYS, A. Introduction to the theory of transport systems (Transporto sistemos teorijos ivadas). Vilnius: Technika, 1997. 228 p. (in Lithuanian).

6. LINGAITIS, L. P. Exploitation of locomotives (Lokomotyvų eksploatavimas). Vilnius: Technika, 1997. 227 p. (in Lithuanian).

7. GRIDIUŠKO, V. I. Economics, organization and planning of rolling stock fleet (Экономика, организация и планирование вагонного хозяйства). Moscow: Transport, 1980. 278 p. (in Russian).

8. BODIN, L.; MINGOZZI, A.; BALDACCI, R.; BALL, M. The rollon-rollof vehicle routing problem. Transportation Science, August 2000, Vol 34, No 3.

9. CRAINIC, T. G.; FLORIAN, M.; LEAR, J.-E. A model for the strategic planning of national freight transportation by rail. Transportation Science, February 1990, Vol 24, No 1.

10. ASSAD, A. A. Models for rail transportation. Transportation Research, 1980, Vol 14, p. 205-220.

11. ALFIERI, A.; GROOT, R.; KROON, L. G.; SCHRIJVER, A. Efficient circulation of railway rolling stock. ERIM Research Report ERS-2002-110-LIS, Erasmus University Rotterdam, Netherlands, 2002. $68 \mathrm{p}$.

12. Website of JSC "Lithuanian Railways" - www.litrail.lt

13. BUTKEVIČIUS, J.; LINGAITIS, L. P.; VAIČIŪNAS, G. Rolling stock planning for passenger transportation. Transport, 2004, Vol XIX, No 5, p. 202-206.

14. LINGAITIS, L. P.; BUTKEVIČIUS, J.; VAIČIŪNAS, G. Strategic planning of passenger transportation by rail transport. Vilnius: Technika, 2003. 125 p. (in Lithuanian). 